\title{
Transtracheal air in the treatment of obstructive sleep apnoea hypopnoea syndrome
}

\author{
F Sériès, J La Forge, N Lampron, Y Cormier
}

\begin{abstract}
A 49 year old woman with typical obstructive sleep apnoea hypopnoea syndrome underwent an unsuccessful trial with continuous positive airway pressure (CPAP) followed by uvulopalatopharyngoplasty with septorhinoplasty, treatment with protriptyline, and a second CPAP trial that was abandoned. Transtracheal air was then given and normalised sleep and breathing at a flow rate of $51 / \mathrm{min}$. A sustained clinical improvement was observed at follow up visits. Transtracheal air could represent a simple and effective alternative to tracheotomy in patients with obstructive sleep apnoea hypopnoea syndrome in whom conventional treatments fail.

(Thorax 2000;55:86-87)
\end{abstract}

Keywords: obstructive sleep apnoea; hypersomnolence; transtracheal air; pneumatic splinting

Unité de recherche, Centre de

Pneumologie, Hôpital

Laval, Université

Laval, Québec,

G1V 4G5 Canada

F Sériès

J La Forge

N Lampron

Y Cormier

Correspondence to:

Dr F Sériès.

Received 26 November 1997 Returned to authors

12 January 1998

Revised manuscript received

3 February 1998

Accepted for publication

13 March 1998 was found with transtracheal air. ${ }^{7}$ A trial was undertaken using a moderate airflow to determine whether increasing the flow rate could further improve obstructive breathing disorders via pneumatic splinting of upper airway structures.

We report the case of a patient with obstructive SAHS who had been unsuccessfully treated with conventional treatments and whose breathing disorders were completely reversed with transtracheal air.

\section{Case report}

A 49 year old obese white woman (body mass index (BMI) $30.3 \mathrm{~kg} / \mathrm{m}^{2}$ ) was first evaluated in May 1989. She was treated for systemic hypertension with verapamil and had undergone an adenoidectomy during childhood. Her symptoms were characteristic of obstructive SAHS. Examination of the upper airway revealed a deviation of the nasal septum, macroglossia, and a posterior position of the soft palate. Thyroid function, pulmonary function tests, and arterial blood gas tensions were normal. A sleep study confirmed the diagnosis of obstructive SAHS (table 1). All apnoeic and hypopnoeic events were obstructive in type.

CPAP was initiated at home at a pressure of $7 \mathrm{~cm} \mathrm{H}_{2} \mathrm{O}$ but it was rapidly terminated due to mask and pressure discomfort. Uvulopalatopharyngoplasty (UPPP) and septorhinoplasty were then performed but a sleep study carried out four months later showed no improvement in nocturnal sleep disorders (table 1). The patient refused CPAP and a mandibular prosthesis. Protriptyline was initiated in a daily dose of $20 \mathrm{mg}$ with no improvements in clinical symptoms and nocturnal breathing (table 1). Another trial with CPAP was therefore performed at an effective pressure level of $10 \mathrm{~cm} \mathrm{H}_{2} \mathrm{O}\left(\mathrm{BMI}\right.$ now $\left.32.6 \mathrm{~kg} / \mathrm{m}^{2}\right)$. The treatment was well tolerated during the first three

Table 1 Results of the different sleep studies

\begin{tabular}{|c|c|c|c|c|c|c|c|}
\hline & $\begin{array}{l}\text { Diagnosis } \\
\text { (Fuly 1989) }\end{array}$ & $\begin{array}{l}\text { First CPAP trial } \\
\text { (fuly 1989) }\end{array}$ & $\begin{array}{l}\text { UPPP (fuly } \\
1992)\end{array}$ & $\begin{array}{l}\text { Protriptyline } \\
\text { (October 1992) }\end{array}$ & $\begin{array}{l}\text { Second CPAP trial } \\
\text { (October 1992) }\end{array}$ & $\begin{array}{l}\text { Follow up } \\
\text { (Fanuary 1997) }\end{array}$ & $\begin{array}{l}\text { Transtracheal air } \\
\text { (fanuary 1997) }\end{array}$ \\
\hline Total sleep time (TST) (h) & 6.7 & 5.3 & 3.7 & 5.4 & 7.6 & 7.0 & 7.5 \\
\hline Stage I-II (\% TST) & 71.1 & 39.1 & 71.9 & 78.2 & 48.7 & 76.0 & 51.2 \\
\hline Stage III-IV (\% TST) & 15.5 & 30.5 & 15.5 & 12.0 & 31.0 & 10.1 & 32.7 \\
\hline Stage REM (\% TST) & 13.4 & 30.4 & 12.6 & 9.8 & 20.3 & 13.9 & 16.1 \\
\hline Apnoea + hypopnoea index (no./h) & 52.0 & 14.6 & 55.0 & 56.2 & 11.3 & 48.1 & 7.2 \\
\hline Arousal index (no./h) & - & - & 45.0 & 55.0 & 10.0 & 54.7 & 8.6 \\
\hline$\%$ TST $<90 \% \mathrm{SaO}_{2}$ & 31.5 & 4.7 & 40.0 & 45.7 & 3.0 & 21.6 & 1.6 \\
\hline
\end{tabular}

$\mathrm{CPAP}=$ continuous positive airway pressure; UPPP = uvulopalatopharyngoplasty 
months but the patient did not return for the follow up visit.

She was re-evaluated four years later following definitive interruption of CPAP therapy (table 1). The therapeutic alternatives were reviewed and it was decided to evaluate transtracheal air before proceeding to a tracheotomy. A Scoop II $^{\circledR}$ catheter was inserted under local anaesthesia. ${ }^{6}$ Repetitive night time oximetry measurements were carried out at different flow levels to determine the effective flow rate. Periodic desaturations persisted at $1.5 \mathrm{l} / \mathrm{min}$ and $3 \mathrm{l} / \mathrm{min}$ although they improved at the higher flow rate (6\% recording time below $90 \%$ $\left.\mathrm{SaO}_{2}\right)$. These events were completely abolished at a flow rate of $5 \mathrm{l} / \mathrm{min}$. At this flow rate the sleep structure and nocturnal breathing disorders normalised. The shape and dimensions of the upper airway measured by computerised tomography during wakefulness did not change with increasing airflow. The patient was sent home with this treatment using an oxygen concentrator without a molecular filter as an airflow generator. Sustained clinical improvement was observed at follow up visits. Unfortunately, several episodes of skin infection around the catheter stoma occurred during the following months that led to withdrawal of the transtracheal catheter after 11 months of use, and a tracheotomy was then performed.

\section{Discussion}

Transtracheal air may represent an effective treatment for obstructive SAHS. There may be several reasons for the apparent discrepancy between our findings and previously published results with transtracheal air in obstructive SAHS. ${ }^{7}$ A flow rate of $21 / \mathrm{min}$ and $31 / \mathrm{min}$ was used in previous studies. In our patient periodic desaturations ${ }^{8}$ persisted at suboptimal flow rates. This suggests that the effectiveness of transtracheal air in obstructive SAHS is dependent on the flow rate. Another important difference is that the transtracheal flow rate was previously adjusted to maintain $\mathrm{SaO}_{2}$ above $90 \%$. Since transtracheal air may increase the lung volume, it may act as passive lung inflation and improve apnoea/hypopnoea related falls in $\mathrm{SaO}_{2}$ with persisting abnormal respiratory disturbances ${ }^{9}$ at a moderate rate of flow.

Previous reports concluded that the effectiveness of transtracheal oxygen is mainly the result of a stabilisation of chemoreceptor activity. Our results suggest that the mechanical effects of transtracheal air can prevent obstruction of the upper airway. We speculate that it may act as an autocontrolled intrathoracic CPAP. With transtracheal air the changes in intrathoracic pressure should be determined by the spontaneous ventilatory pattern and by expiratory upper airway resistance, excess flow being freely expired through the open upper airway. Inspiratory and expiratory upper airway resistance both progressively increase during the breathing cycles that precede the onset of obstructive apnoea..$^{10}$ As soon as these resistances increase, transtracheal air increases intrathoracic and extrathoracic airway pressure, resulting in lung inflation and in pneumatic splinting of the upper airway. Any rise in upper airway resistance will therefore be automatically counterbalanced by an increase in the passive transmural dilating force and maintenance of patency of the upper airway.

Transtracheal air could represent a simple and effective alternative to tracheotomy and could therefore be used in selected motivated patients in whom conventional treatments have failed.

$1 \mathrm{He}$ J, Kryger $\mathrm{MH}$, Zorick FJ, et al. Mortality and apnea index in obstructive sleep apnea. Chest 1988;94:9-14.

2 Sullivan CE, Issa FQ, Berthon-Jones M, et al. Reversal of obstructive sleep apnea by continuous positive airway pressure applied through the nares. Lancet 1981;i:862-5.

3 Fujita S, Conway W, Zorick FJ, et al. Evaluation of the effectiveness of uvulopalatopharyngoplasty. Laryngoscope 1985; 95:70-4.

4 O'Sullivan RA, Hillman DR, Mateiljan R, et al. Mandibular advancement splint: an appliance to treat snoring and obstructive sleep apnea. Am $\mathcal{f}$ Respir Crit Care Med 1995;151:194-8.

5 Chistofer KL, Spofford BT, Peturn MD, et al. A program for transtracheal oxygen delivery: assessment of safety and efficacy. Ann Intern Med 1987;107:802-8.

6 Chauncey JB, Aldrich MS. Preliminary findings in the treatment of obstructive sleep apnea with transtracheal oxygen. Sleep 1990;13:167-74

7 Farney RJ, Walker JM, Elmer JC, et al. Transtracheal oxygen, nasal CPAP, and nasal oxygen in five patients with obstructive sleep apnea. Chest 1992;101:1228-35.

8 Sériès F, Marc I, Cormier Y, et al. Utility of nocturnal home oximetry for case finding in patients with suspected sleep apnea-hypopnea syndrome. Ann Intern Med 1993;119:44953.

9 Sériès F, Cormier Y, Lampron N, et al. Influence of lung volumes in sleep apnoea. Thorax 1989;44:52-7.

10 Sanders $\mathrm{MH}$, Moore SE. Inspiratory and expiratory partitioning of airway resistance during sleep in patients with sleep apnea. Am Rev Respir Dis 1983;127:554-8. 